\title{
La revolución del cómic adulto en España
}

\author{
Reseña de: VILCHES, G. (coord.), Del boom al crack. La explosión del \\ cómic adulto en España (1977-1995), Barcelona, Diminuta Editorial, 2018
}

Elena Masarah

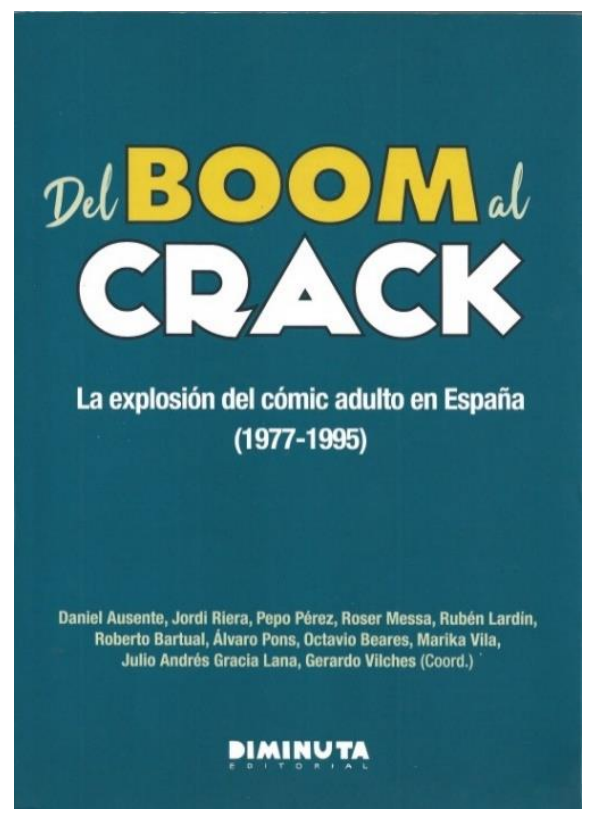

El intenso periodo histórico que se abrió en España con la muerte de Franco en 1975, y que constituyó el final de una dictadura de cuatro largas décadas y los inicios de la transición a la actual democracia, se caracterizó por las intensas transformaciones políticas, sociales y culturales que vivió el país. Dentro de estas últimas, el cómic pasó por un momento crucial de su historia, en unos años de rápidos y complejos cambios que marcarían el devenir del medio en las décadas siguientes. Algo así como una revolución. Y, como todas las revoluciones que se precien, cuenta con una

denominación que la define a la perfección: el «boom del cómic adulto».

¿Por qué boom y por qué «del cómic adulto»? Lo cierto es que las décadas de los sesenta y los setenta, a nivel internacional, supusieron para la historieta un momento clave por dos aspectos: por un lado, fue el inicio de la creación y la producción de un tipo de obra que ya no iba dirigida al público infantil y juvenil, como así había sido tradicionalmente; y, por otro, el cómic comenzó a tomar conciencia de ser algo más que un medio de masas: es decir, se le empezó a conceder el valor artístico que hasta entonces le había sido negado. En España, esos cambios llegaron con cierto retraso, motivados por la coyuntura política y social, y se concentraron en un periodo de tiempo relativamente corto, algo más de una década. Además, fueron el principio de una etapa marcada por la apertura a la diversidad, tanto de proyectos editoriales como de estilos artísticos, y por la intensidad de los cambios acaecidos en la industria del tebeo. Es este contexto histórico, social y cultural 
el que analiza la obra Del boom al crack. La explosión del cómic adulto en España (1977-1995).

Coordinado por el historiador Gerardo Vilches, se trata de un conjunto de artículos escritos desde la óptica diversa que aportan la investigación, el periodismo y las vivencias en primera persona de los propios autores. Así, como si de piezas de un puzle se tratara, estas voces configuran una visión panorámica de todo el periodo y contribuyen, además, con significativas novedades para la historiografía que ha abordado esta revolución.

La primera de estas renovaciones es la cronológica: el periodo temporal escogido desborda los parámetros tradicionales para extenderse en el tiempo. Así, 1995 es la fecha en la que echa el cierre Cimoc (1979-1980; 1981-1995), editada por Norma, pero simboliza a su vez el final (también a nivel internacional) de un modelo de mercado y de un formato, el de la revista. Si bien El Víbora (1979-2005), la mítica cabecera, siguió publicándose hasta bien entrada la década de los dos mil, la investigación de Julio A. Gracia Lana pone sobre la mesa ese momento bisagra, en los primeros años noventa, en el que las revistas empezaron a afrontar su desaparición, de manera progresiva, en un contexto de crisis económica y cambio en los hábitos de ocio. De este modo, y a través del enfoque sobre cómo afectó todo ello a las carreras artísticas de diversos autores y las pervivencias (y supervivencias) de nuevas cabeceras que se resistían ante el avance del cambio, el texto de Gracia analiza unos años clave que tienden puentes con el futuro, con el desarrollo posterior del mercado español y con el surgimiento, ya en el siglo XXI, de ese otro formato denominado (no sin polémica) novela gráfica.

A este respecto de la cronología, cabe mencionar que, aunque el subtítulo de la antología alude a 1977 como inicio del periodo analizado (dado que en ese año nació Totem, 1977-1986, la revista editada por Nueva Frontera), la obra comienza con un ensayo de Daniel Ausente que repasa la historia del cómic español desde la posguerra hasta la creación y el desarrollo de Selecciones Ilustradas, la agencia de Josep Toutain. Es un texto, el de Ausente, crítico e ingenioso, que se aleja de cualquier mirada nostálgica y melancólica y que contextualiza sin tabúes los inicios de ese caldo de cultivo que conformó «la burbuja» de las revistas de cómic adulto.

El análisis central del periodo lo plantean una serie de artículos que tienen, por un lado, a algunos de los autores y, por otro, a las revistas y a ciertos ejes temáticos como objetivo de sus investigaciones. Entre los primeros se sitúan los de Roberto Bartual y Jordi Riera, que centran su mirada 
en dos de los protagonistas más señalados: Carlos Giménez y Enric Sió, cuya obra se enmarca en los inicios de la conciencia autoral. En el caso del madrileño, el punto de vista se centra en algunos de sus trabajos, cuyo nexo común es que parten de lo que ahora denominamos memoria histórica. En cambio, el acercamiento a la figura de Sió se realiza a través de un repaso a su biografía, que revela el choque entre sus aspiraciones artísticas y el sector del cómic al que se adscribía.

A través de una profunda revisión de las principales cabeceras de ficción de género, desde Comix Internacional y Totem, pasando por la era Toutain hasta llegar a Rambla, Metropol y K.O. Comics, Pérez desarticula la idea que considera estas publicaciones de género como adultas, puesto que, en su opinión, las consumía más bien un público juvenil, adolescente y universitario. Por contra, Álvaro Pons, que estudia el nacimiento y desarrollo de Cairo (1981-1991), editada por Norma y máximo exponente de la «línea clara», considera que esta publicación, que buscó un espacio propio entre la tradición franco-belga y la vanguardia y que destacó al apostar por autores españoles, reivindicaba el cómic de género y aventuras para un público adulto, en consonancia con su objetivo de recuperar el legado de Tintín, más allá de las polémicas.

Un eje temático de estudio innovador es el que desarrolla Marika Vila, quien firma un artículo sobre el enfoque masculino y sexista de las revistas que protagonizaron el boom, y que se nutre de su propia experiencia personal. Marika, quien vivió desde la primera línea la eclosión de la «revolución» del cómic adulto, se ha especializado en los estudios de género y feminismo, gracias a lo cual ha sabido trazar una certera imagen de la situación y la aportación al medio de aquellas mujeres pioneras en el cómic de la transición. La autora se posiciona desde un presente que demanda la visibilidad y el conocimiento de la herstory del cómic patrio para reivindicar así a Núria Pompeia, a las dibujantes y guionistas que entraron en El Víbora, y a esas otras autoras que, además, formaron parte del primer impulso de denuncia del machismo en el cómic, entre las que destacaron Montse Clavé, Mariel Soria y ella misma.

Con un toque de ensayo periodístico, Roser Messa elabora una auténtica historia del underground barcelonés previo al nacimiento de $E l$ Víbora en 1979: de este modo, analiza publicaciones clave para este movimiento como Mata Ratos (1965-1974), a la que considera una «precursora olvidada», el famoso Rrollo Enmascarado (1973), Star (19741980) e, incluso, la reivindicativa Butifarra! (1975-1977 en su primera etapa). 
Fue la llegada de la revista creada por Josep $M{ }^{\text {a }}$ Berenguer, que lideró la «línea chunga» frente a Cairo, la que oficializó, de algún modo, la contracultura, llegando a ser la revista más vendida.

Sin embargo, la incursión en la historia de El Víbora la aporta la experiencia personal de Emilio Bernárdez, hoy editor de La Cúpula. Porque, en efecto, la otra gran contribución del libro es la inclusión de entrevistas con editores y autores de la época, a modo, casi, de fuente primaria. Entre los primeros, las conversaciones mantenidas con Bernárdez, por parte de Rubén Lardín, y con Rafael Martínez (editor de Norma), realizada por Daniel Ausente, destacan por ser la primera vez que ambos aportan su visión como protagonistas del proceso, desde una posición histórica nada mediática. Al contrario que Toutain, cuyo choque con el cambio generacional, con la nueva hornada de autores que no provenían de las agencias, se evidencia en el caso de Miguelanxo Prado (entrevistado por Octavio Beares), quien relata algunos encontronazos con el editor, lo que muestra otro aspecto más de uno de los actores principales de esta escena.

En una visión global de la obra, quizá la carencia más evidente se perciba en la no inclusión de un estudio específico que sitúe en este contexto las revistas satíricas, principalmente los casos de El Jueves y El Papus, puesto que constituyeron ese otro gran foco de publicaciones dirigidas a público adulto y engrosaron y bebieron de esa «burbuja» que fue el boom del cómic en los ochenta. Pero, en definitiva, la diversidad de perspectivas y voces, la apuesta por la inclusión tanto de textos teóricos como de entrevistas a protagonistas de aquel momento, y el enfoque de análisis crítico, con un evidente esfuerzo por huir de las nostalgias, los prejuicios y las posiciones reduccionistas del pasado, consiguen que la aportación más innovadora y notoria del libro sea su propia conformación, al mismo tiempo, como fuente historiográfica y como memoria oral de un periodo definitorio del cómic español. 